\title{
ROLE OF OFFICE HYSTEROSCOPY IN EVALUATION OF PERIMENOPAUSAL BLEEDING PATIENTS ATTENDING OUTPATIENT GYNECOLOGIC CLINIC
}

\author{
By \\ Alaa H. Mohamed, Mohammed T. Ismail, Yousef A. Abu Shady and \\ Taher M. Mostafa \\ Department of Obstetrics and Gynaecology, Faculty of Medicine, Al-Azhar University \\ Corresponding author: Alaa. H. Mohamed,
}

Mobile: 01006789604, E-mail: dr_alaa_hassan44@yahoo.com

\begin{abstract}
Background: Perimenopausal bleeding is a real clinical challenge facing gynecologists, which should indicate suspicion of endometrial malignant changes development and needs accurate evaluation of endometrium and uterine cavity.

Objective: To provide a clear understanding of the value of office hystroscopy as a diagnostic tool during assessment of women with perimemnopausal bleeding.

Patient and Methods: This prospective study included case records of 50 women with perimenopausal bleeding undergone office hysteroscopy and endometrial biopsy between 2017 and 2019 at Al Sayed Galal Hospital, Al-Azhar University, Cairo, Egypt.

Results: Sonographic findings of malignant or premalignant endometrium showed $25 \%$ sensitivity and $100 \%$ specificity for endometrial thickness $\geq 17 \mathrm{~mm}$ and $100 \%$ sensitivity and $58.7 \%$ specificity for endometrial thickness $\leq 10 \mathrm{~mm}$. Sonographic findings of abnormal endometrial pathology showed $37.06 \%$ sensitivity and $100 \%$ specificity for endometrial thickness $\geq 10 \mathrm{~mm}$ and $88.24 \%$ sensitivity and 57.14 specificity for endometrial thickness $\leq 7 \mathrm{~mm}$. Hysteroscopic findings of malignant or premalignant showed $100 \%$ sensitivity and $76.09 \%$ specificity for endometrial thickness, $60 \%$ sensitivity and 93.48 specificity for endometrial polyp , $100 \%$ sensitivity and $100 \%$ specificity for endometrial mass and 50\% sensitivity and 95.6\% specificity for hypervascular endometrium .Hystroscopic findings of abnormal endometrial pathology showed $77.8 \%$ sensitivity and $92.7 \%$ specificity for thick endometrium, $80 \%$ sensitivity and $92.6 \%$ specificity for endometrial polyp, $22.2 \%$ and $100 \%$ specificity for endometrial mass, $22.2 \%$ sensitivity and $95.1 \%$ specificity for hypervascular endometrium.

Conclusion: Office hysteroscopy can be considered as a golden standard tool in diagnosis and management of perimenoipausal bleeding. It is valuable in assessment of endometrium and helpful in management planning.
\end{abstract}

Key words: Office Hysteroscopy, perimenopausal bleeding, gynecologic clinic.

\section{INTRODUCTION}

Perimenopausal bleeding is defined as any bleeding from genital tract which has any deviation from normal frequency, cyclicity, duration and amount of flow at or above 40 yrs. of age, approximately $20 \%$ of patients presenting to the gynaecologist have abnormal uterine bleeding and this proportion rises to $69 \%$ 
during Perimenopausal age group (Seshadri, (2016).

Abnormal uterine bleeding is one of the most common clinical problems in gynecology. Up to $33 \%$ of women referred to gynecological outpatient clinics have this problem and the proportion rises more in peri- and postmenopausal women. This condition has enormous consequences with regard to social life, morbidity and clinical workload (ACOG, 2012).

Fibroids or polyps are the most common cause of anatomic AUB; Twenty to forty percent of women have fibroids. These women might present with abnormal bleeding, anemia, pain, and occasionally infertility (Rashid et al., 2010).

Clinical definition is the phase preceding the onset of menopause, general occurring around 40-45 years of age during which the regular cycle of women transitions to pattern of irregular cycles (Nanda et al., 2013).

There is a wide range of diagnostic modalities to delineate cause of Perimenopausal bleeding like dilatation and curettage, transvaginal ultrasonography, endometrial biopsy and hysteroscopy. Due to high accuracy and patient compliance, transvaginal sonography (TVS) allows detailed assessment of anatomical abnormalities of the uterus and endometrium (Kotdawala et al., 2013).

In addition, pathologies of the myometrium, cervix, tubes, and ovaries may be assessed. This investigative modality may assist in the diagnosis of endometrial polyps, leiomyomas, uterine anomalies, and generalized endometrial thickening associated with hyperplasia and malignancy (Singh et al., 2013).

The present study was designed to explore the role of office hysteroscopy in perimenopausal bleeding in patients attending outpatient gynecologic clinic.

\section{PATIENTS AND METHODS}

This study was a retrospective study involving case records of 50 women with perimenopausal bleeding undergone office hysteroscopy and endometrial biopsy between 2017 and 2019 at Al Sayed Galal Hospital, Al Azhar University, Cairo, Egypt.

Included women in this study were within age range of 40 to 45 years old. The age of perimenopause was defined by ACOG as the phase leading up to the point of menopause that can last for up to 10 years. During perimenopause, shifts in hormone levels can affect the endometrium causing abnormal endometrial growth pattern. All women in this study were complaining of abnormal perimenopausal bleeding and didn't take hormone replacement therapy and had no positive personal history of cancer of genital tract. Most of the women (39 women of the 50) in this study were suffering from comorbidities (diabetes mellitus, hypertension and chronic liver disease). These morbdidties have their influence on uterine and endometrial vascularity and may consequently affect the endometrial pattern and activity. Each patient underwent transvaginal ultrasound to define endometrial thickness, and all of the included patients had suspected endometrial pathology. Endometrial thickness was measured by calculating the 
maximum distance between the two lines of the endometrium/myometrium interface in a sagittal scan. The 50 women in this study had no bleeding dyscarysis/ coagulopathy, e.g. platelet dysfunction, Von Willebrand and acute leukemia. All women were not taking anticoagulant drugs.

All study subjects have undergone hysteroscopy by usage of paracervical block (an anesthetic procedure used in obstetrics and gynecology, in which a local anesthetic is injected at a depth of 3$7 \mathrm{~mm}$ alongside the vaginal portion of the cervix in the vaginal fornices.) by administering lidocaine and endometrial biopsy was undertaken from all cases for histo-pathological examination, and full clinical history and examination.

\section{Statistical analysis:}

Recorded data were analyzed using the statistical package for social sciences, version 20 (SPSS Inc., Chicago, Illinois, USA). Receiver operating characteristic curve (ROC) was used to assess the best cut off point with its sensitivity, specificity, positive predictive value (PPV), negative predictive value (NPV) and area under curve (AUC). The confidence interval was set to $95 \%$ and the margin of error accepted was set to $5 \%$. So, the p-value was considered significant when $\mathrm{p} \leq 0.05$.

\section{RESULTS}

Endometrial thickness range by sonographic assessment was (6-22) $\mathrm{mm}$ with Mean \pm SD $(10.5 \pm 3.17)$ mm (Figure 1). By hysteroscopy, endometrial thickness was normal in 35 women (70\%), while it was thick in 15 women $(30 \%)$. Regarding hysteroscopic Endometrial Lesions, 45 women (90\%) had no lesions, 3 women (6\%) had endometrial polyp, 2 women had masses (4\%). During evaluation of Endometrial Vascularity by hysteroscope, we found 46 women (92\%) had normal endometrial vascularity, while we detected hypervascular endometrium in 4 women (8\%). Concerning endometrial pathology, 7 women (14\%) had atrophic endometrium, 34 women $(68 \%)$ had proliferative endometrium, 7 women (14\%) had simple endometrial hyperplasia without atypia, 1 woman $(2 \%)$ had endometrial hyperplasia with atypia, and 1 woman (2\%) had endometrial carcinoma (Table 1).

Table (1): Sonographic, Hysteroscopic and Pathological Findings in Included Women 
ALAA H. MOHAMED et al.,

\begin{tabular}{|l|c|}
\hline Sonographic Endometrial Thickness (mm) & $6-22$ \\
Range & $10.5 \pm 3.17$ \\
\hline Hean \pm SD & \\
\hline Normal & $35(70 \%)$ \\
Thick & $15(30 \%)$ \\
\hline Hysteroscopic Endometrial Lesion & \\
None & $45(90 \%)$ \\
Polyp & $3(6 \%)$ \\
Mass & $2(4 \%)$ \\
\hline Hysteroscopic Endometrial Vascularity & \\
Normal & $46(92 \%)$ \\
Hypervascular & $4(8 \%)$ \\
\hline Endometrial Pathology & \\
Atrophic & $7(14 \%)$ \\
Proliferative & $34(68 \%)$ \\
Simple Endometrial Hyperplasia without Atypia & $7(14 \%)$ \\
Endometrial Hyperplasia with Atypia & $1(2 \%)$ \\
Endometrial Carcinoma & $1(2 \%)$ \\
\hline
\end{tabular}

SD standard deviation

Data wer presented as range, mean $\pm \mathrm{SD}$; or frequency (percentage)

ROC curve revealed that there is statistical significant value of sonographic endometrial thickness as a predictor of malignant (endometrial carcinoma) or premalignant (endometrial hyperplasia with atypia) endometrial pathology in included women, as denoted by the significantly large area under the curve [AUC $=0.845,95 \% \mathrm{CI}$ (0.715 to 0.932), $\mathrm{p}$ value $<0.001]$ (Figure 1). 


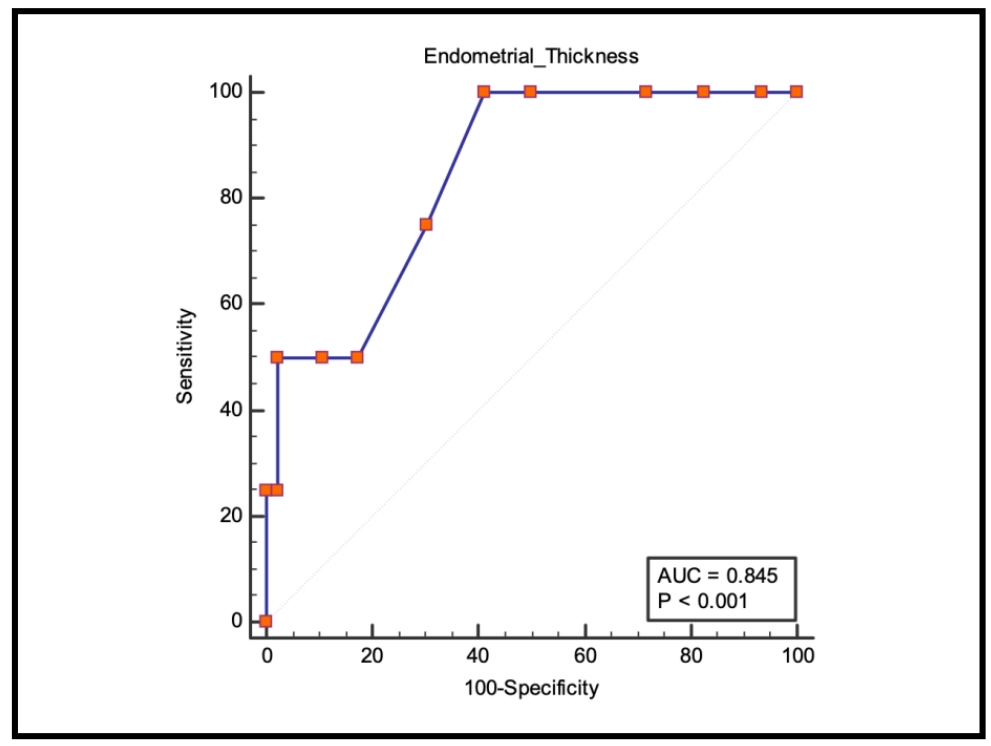

Figure (1): ROC Curve for Endometrial Thickness as a Predictor of Malignant or Premalignant Endometrial Pathology in Included Women

According to this ROC curve, and among included women, an endometrial thickness $\geq 17 \mathrm{~mm}$ was statistically significantly associated with malignant or premalignant endometrial pathology with a $100 \%$ specificity and an infinite $\mathrm{LR}+$, while an endometrial thickness $<10 \mathrm{~mm}$ with associated with no malignant or premalignant lesion with a $100 \%$ sensitivity and a nil LR- and among included women, an endometrial thickness $\geq 10 \mathrm{~mm}$ was statistically significantly associated with abnormal endometrial pathology with a $100 \%$ specificity and an infinite LR+, while an endometrial thickness $<7 \mathrm{~mm}$ with associated with no abnormal endometrial pathology with a sensitivity of $88.24 \%$ and an LR- of 0.21(Table 2).

Table (2): Validity of endometrial thickness as a Predictor of malignant, premalignant and abnormal endometrial pathology in included women

\begin{tabular}{|l|c|c|c|c|}
\hline $\begin{array}{l}\text { Sonographic } \\
\text { endometrial } \\
\text { Thickness }\end{array}$ & Sensitivity & Specificity & LR+ & LR- \\
\hline $\mathbf{1 7} \mathbf{~ m m}$ & $\begin{array}{c}25 \% \\
(0.6 \text { to } 80.6)\end{array}$ & $\begin{array}{c}100 \% \\
(92.3 \text { to } 100)\end{array}$ & $\infty$ & $\begin{array}{c}0.75 \\
(0.4 \text { to } 1.3)\end{array}$ \\
\hline$\leq \mathbf{1 0} \mathbf{~ m m}$ & $\begin{array}{c}100 \% \\
(39.8 \text { to } 100)\end{array}$ & $\begin{array}{c}58.7 \% \\
(43.2 \text { to } 73)\end{array}$ & $\begin{array}{c}2.42 \\
(1.7 \text { to } 3.4)\end{array}$ & 0.0 \\
\hline $\mathbf{1 0} \mathbf{~ m m}$ & $\begin{array}{c}37.06 \% \\
(29.8 \text { to } 64.9)\end{array}$ & $\begin{array}{c}100 \% \\
(59 \text { to } 100)\end{array}$ & $\infty$ & $\begin{array}{c}0.53 \\
(0.4 \text { to } 0.7)\end{array}$ \\
\hline$\leq \mathbf{7} \mathbf{~ m m}$ & $\begin{array}{c}88.24 \% \\
(57.5 \text { to } 96.7)\end{array}$ & $\begin{array}{c}57.14 \% \\
(29 \text { to } 69.3)\end{array}$ & $\begin{array}{c}2.06 \\
(0.9 \text { to } 4.9)\end{array}$ & $\begin{array}{c}0.21 \\
(0.07 \text { to } 0.6)\end{array}$ \\
\hline
\end{tabular}

We studied the validity of different hysteroscopic findings in prediction of malignant (endometrial carcinoma) or premalignant (endometrial hyperplasia 
with atypia) endometrial pathology in included fifty women. We found hysteroscopc thick endometrium as a predictor of malignant or premalignant endometrial pathology had $100 \%$ sensitivity, $76.09 \%$ specificity, LR+ 4-18, and nil LR-. Hysteroscopic endometrial polyp as a predictor had sensitivity of $60 \%$, specificity of $93.48 \%, L R+0.0$ and LR- 1.07. Hysteroscopic endometrial mass as a predictor had $100 \%$ sensitivity and $100 \%$ specificity, with infinite LR+ and LR- 0.0. Hysteroscopic hypervascular endometrium as predictor had sensitivity and specificity of $50 \%$ and $95.6 \%$ respectively, with $\mathrm{LR}+11.5$ and LR- 0.52 and the validity of different hysteroscopic findings in prediction of abnormal endometrial pathology (endometrial hyperplasia with or without atypia; or endometrial carcinoma) in included women. As a predictor of abnormal endometrial pathology, hysteroscopic thick endometrium had sensitivity of $77.8 \%$, specificity of $92.7 \%$, LR+ 10.6 and LR- 0.24. Hysteroscopic endometrial polyp had $80 \%$ sensitivity, $92.6 \%$ specificity, nil LR+ and LR- 1.1. Hysteroscopic endometrial mass had sensitivity and specificity of $22.2 \%$ and $100 \%$ respectively, infinite LR+ and LR0.78. Hysteroscopic hypervascular endometrium as a predictor, had $22.2 \%$ sensitivity, $95.1 \%$ specificity, LR+ 4.6 and LR- 0.82 (Table 3).

Table (3): Validity of Hysteroscopic Findings as a Predictor of malignant, premalignant and abnormal endometrial Pathology in Included Women

\begin{tabular}{|c|c|c|c|c|}
\hline & Sensitivity & Specificity & LR+ & LR- \\
\hline \multicolumn{5}{|c|}{ Malignant or Premalignant Endometrial Pathology } \\
\hline $\begin{array}{l}\text { Hysteroscopic Thick } \\
\text { Endometrium }\end{array}$ & $\begin{array}{c}100 \% \\
\text { (39.7 to } 100)\end{array}$ & $\begin{array}{c}76.09 \% \\
\text { (61.2 to } 87.4)\end{array}$ & $\begin{array}{c}4.18 \\
\text { (2.5 to } 7.01)\end{array}$ & 0.0 \\
\hline $\begin{array}{l}\text { Hysteroscopic } \\
\text { Endometrial Polyp }\end{array}$ & $\begin{array}{c}60 \% \\
(0.0 \text { to } 84.19)\end{array}$ & $\begin{array}{c}93.48 \% \\
\text { (82.1 to } 98.6)\end{array}$ & 0.0 & $\begin{array}{c}1.07 \\
\text { (0.99 to } 1.6)\end{array}$ \\
\hline $\begin{array}{l}\text { Hysteroscopic } \\
\text { Endometrial Mass }\end{array}$ & $\begin{array}{c}100 \% \\
(15.8 \text { to } 100)\end{array}$ & $\begin{array}{c}100 \% \\
\text { (91.7 to } 100)\end{array}$ & $\infty$ & 0.0 \\
\hline $\begin{array}{l}\text { Hysteroscopic } \\
\text { Hypervascular } \\
\text { Endometrium }\end{array}$ & $\begin{array}{c}50 \% \\
\text { (6.9 to } 93.2)\end{array}$ & $\begin{array}{c}95.6 \% \\
\text { (85.2 to } 99.5)\end{array}$ & $\begin{array}{c}11.5 \\
(2.2 \text { to } 61.3)\end{array}$ & $\begin{array}{c}0.52 \\
(0.19 \text { to } 1.4)\end{array}$ \\
\hline \multicolumn{5}{|c|}{ Abnormal Endometrial Pathology } \\
\hline $\begin{array}{l}\text { Hysteroscopic Thick } \\
\text { Endometrium }\end{array}$ & $\begin{array}{c}77.8 \% \\
\text { (39.9 to } 97.2 \text { ) }\end{array}$ & $\begin{array}{c}92.7 \% \\
\text { (80.1 to } 98.5)\end{array}$ & $\begin{array}{c}10.6 \\
(3.4 \text { to } 33.4)\end{array}$ & $\begin{array}{c}0.24 \\
(0.07 \text { to } 0.8)\end{array}$ \\
\hline $\begin{array}{l}\text { Hysteroscopic } \\
\text { Endometrial Polyp }\end{array}$ & $\begin{array}{c}80 \% \\
(0.0 \text { to } 63.6)\end{array}$ & $\begin{array}{c}92.6 \% \\
\text { (80.1 to } 98.5)\end{array}$ & 0.0 & $\begin{array}{c}1.1 \\
(0.99 \text { to } 1.2)\end{array}$ \\
\hline $\begin{array}{l}\text { Hysteroscopic } \\
\text { Endometrial Mass }\end{array}$ & $\begin{array}{c}22.2 \% \\
\text { (2.8 to } 60.1)\end{array}$ & $\begin{array}{c}100 \% \\
(91.4 \text { to } 100)\end{array}$ & $\infty$ & $\begin{array}{c}0.78 \\
(0.5 \text { to } 1.1)\end{array}$ \\
\hline $\begin{array}{l}\text { Hysteroscopic } \\
\text { Hypervascular } \\
\text { Endometrium }\end{array}$ & $\begin{array}{c}22.2 \% \\
\text { (2.8 to } 60.1)\end{array}$ & $\begin{array}{c}95.1 \% \\
\text { (83.5 to } 99.4)\end{array}$ & $\begin{array}{c}4.6 \\
(0.7 \text { to } 28.2)\end{array}$ & $\begin{array}{c}0.82 \\
(0.57 \text { to } 1.2)\end{array}$ \\
\hline
\end{tabular}




\section{DISCUSSION}

Perimenopausal bleeding is a real clinical challenge facing gynecologists, which should indicate suspicion of endometrial malignant changes development and needs accurate evaluation of endometrium and uterine cavity. Although uncommon, endometrial polyps may be the potential origin of the malignancy (Balik et al., 2013 and Acmaz et al., 2014). Thus, many tools are arising to reveal the best diagnostic approach and the appropriate management protocol of perimenopausal bleeding. Clinical trials and researches are investigating the accuracy, sensitivity and specificity of these different diagnostic tools, and comparing them with each other, to find the best and the most accurate one (Giannella et al., 2014 and Shor et al., 2019).

Office hysteroscopy did not require hospitalization and anesthesia, which reduced the cost making it an inexpensive choice. It can be performed on an outpatient basis or as a day case procedure with high acceptability and satisfaction from patients (Khrouf et al., 2014).

In the present study, 34\% were free, with no comorbidities while the rest (66\%) had comorbidities, 24\% had hypertension, $26 \%$ had diabetes mellitus and $16 \%$ had chronic liver disease.

There was a statistical significance of sonographic endometrial thickness as a predictor of endometrial malignant/ premaliganat pathological changes. Endometrial thickness $>17 \mathrm{~mm}$ was significant statistically associated with malignant/ premalignant endometrial pathology with $100 \%$ specificity and $25 \%$ sensitivity. On the other hand, endometrial thickness between 10-17 mm was significant statistically associated with endometrial pathology, with $100 \%$ specificity, while endometrial thickness < $7 \mathrm{~mm}$ was associated with no endometrial pathology with sensitivity of $88.24 \%$.

In the present study, office hysteroscopic assessment of endometrium revealed $90 \%$ women had no endometrial lesion, $6 \%$ women had endometrial polyps and $4 \%$ women had masses. Hystroscopic detection of thick endometrium had $77.8 \%$ sensitivity and $92.7 \%$ specificity. In addition, Gkrozou et al. (2015) reported that office hystroscopy in diagnosing both endometrial polyps and masses had both sensitivity and specificity of more than $95 \%$. As a predictor of malignant/ premalignat endometrial changes, hysteroscopic detection of thick endometrium had $100 \%$ sensitivity and $76.09 \%$ specificity.

Regarding endometrial polyps, our calculated specificity of detecting them by office hysteroscopy was $92.6 \%$, while its sensitivity was $80 \%$. Also, hysteroscopic detection of them had $93.48 \%$ specificity in prediction of malignant/premalignant endometrial changes, and $60 \%$ sensitivity. Office hysteroscpy had $22.2 \%$ sensitivity and $100 \%$ specificity in detecting endometrial masses, but it had both sensitivity and specificity of $100 \%$ in prediction of malignant/premalignant endometrial changes. Another study by Shor et al. (2019) revealed 100\% sensitivity and $98.7 \%$ specificity of hysteroscopy in diagnosing endometrial polyps and masses.

Pennant et al. (2017) documented similar findings in their study of the value of hysteroscopic exploration for abnormal 
uterine bleeding. They described diagnostic hysteroscopy as a basic tool allows precise diagnosis of endometrial lesions as polyps and masses. Furthermore, Spadoto-Dias et al. (2016) found office hysteroscopy a sensitive tool to diagnose endometrial polyps and masses and reported its higher sensitivity when compared to curettage in diagnosing these benign endometrial lesions.

In present study, we found $92 \%$ had normal hysteroscopic endometrial vascularity, while $8 \%$ had hypervascular endometrium. The sensitivity of hysteroscopic hypervascular endometrium as a predictor of benign endometrial lesion was $22.2 \%$, while the specificity was $95.1 \%$. As a predictor of malignat/premalignat endometrial pathology, hysteroscopic hypervascular endometrium had a sensitivity of $50 \%$ and a specificity of $95.6 \%$, denoting higher specificity. Dias et al. (2014) concluded that postmenopausal bleeding and endometrial hypervascularity along with vascular atypia at diagnostic hysteroscopy showed a greater association with endometrial cancer.

Shor et al. (2019) studied prediction of malignant endometrial polyps by hysteroscopic features, and they stated that hysteroscopic findings of increased vascularity of endometrial polyps may suggest the diagnosis of malignant polyps. Similar to our findings, they reported higher specificity than sensitivity for hysteroscopic hypervascular endometrial as a predictor of malignant/premalignant endometrial changes.

In this study, we diagnosed atrophic endometrium in $14 \%$, proliferation endometrium in $68 \%$, simple endometrial hyperplasia without atypia in 14\%, endometrial hyperplasia with atypia in $2 \%$, and endometrial carcinoma in $2 \%$. Concerning the woman with endometrial carcinoma and the other one with simple endometrial hyperplasia with atypia, they were both correctly observed and diagnosed in a preliminary form visualized by the operators, and none of the biopsies obtained during hysteroscopy were eventually revealed to be benign in histopathological study. Thus, we reported that office hysteroscopy is valuable in detecting endometrial carcinoma and endometrial hyperplasia with atypia. Additionally, Trojano et al. (2018) reported $66.7 \%$ sensitivity and $100 \%$ specificity of hysteroscopy in diagnosing endometrial hyperplasia, while in diagnosing endometrial carcinoma they reported sensitivity and specificity of $100 \%$ and $98.6 \%$ respectively.

Gkrozou et al. (2015) studied the accuracy of hysteroscopy in diagnosing endometrial carcinoma, and they concluded that hysteroscopic procedures have a high accuracy for detecting endometrial carcinoma. However they reported moderate diagnostic accuracy for endometrial hyperplasia and they explained that as endometrial hyperplasia does not appear with a specific hysteroscopic presentation.

Bourdel at al. (2016) stated that due to lack of morphological diagnostic criteria for endometrial malignant pathologies, hysteroscopic reliability may be influenced by the experience of the operator. They found that sensitivity improves with the observer's experience, but inter-observer agreement and reproducibility of hysteroscopy for 
endometrial malignancies are not satisfying no matter the level of expertise. Therefore, an accurate and complete endometrial sampling is still needed.

However, prior research studies did not show conclusive determination of the accuracy of the histological malignancy grade in a biopsy obtained at outpatient hysteroscopy in comparison to the final pathology result obtained at hysterectomy. As malignant lesions have tendency to bleed during examination, it is possible that the outpatient hysteroscopic procedures are ended prematurely in comparison to inpatient hysteroscopy, which overwhelms the visual challenges by higher fluid pressure and better instrumental tools (Hoshino et al., 2017).

\section{CONCLUSION}

It appears that office hysteroscopy can be considered as a golden standard tool in diagnosis and management of perimenoipausal bleeding. It is valuable in assessment of endometrium and helpful in management planning.

\section{REFERENCES}

1. Acmaz G, Aksoy H, Albayrak E, Baser M, Ozyurt S, Aksoy U and Unal D (2014): Evaluation of endometrial precancerous lesions in postmenopausal obese women--a high risk group? Asian Pac J Cancer Prev; 15: 195-8.

2. Balik G, Kagitci M, Ustuner I, Akpinar F, and Guven ES. (2013): Which endometrial pathologies need intraoperative frozen sections? Asian Pac J Cancer Prev; 14: 6121-5.

3. Bourdel N, Modaffari P, Tognazza E, Pertile R, Chauvet P, Botchorishivili R, Savary D, Pouly JL, Rabischong B and Canis M. (2016): Does experience in hysteroscopy improve accuracy and inter-observer agreement in the management of abnormal uterine bleeding? Surg Endosc , 30: 5558-5564.

4. Dias DS, Bueloni-Dias FN, Dias R, Nahás-Neto J, Petri Nahás EA, Leite NJ, Custódio Domingues MA, Bueno Angela SP and Padovani CR (2014): Usefulness of clinical, ultrasonographic, hysteroscopic, and immunohistochemical parameters in differentiating endometrial polyps from endometrial cancer. J Minim Invasive Gynecol., 21(2):296-302.

5. Giannella L, Mfuta K, Setti T, Boselli F, Bergamini E and Cerami L (2014): Diagnostic accuracy of endometrial thickness for the detection of intrauterine pathology and appropriateness of performed hysteroscopies among asymptomatic postmenopausal women. Eur J Obstet Gynecol Reprod Biol, 177:29-33.

6. Gkrozou F, Dimakopoulos G, Vrekoussis T, Lavasidis L, Koutlas A, Navrozoglou I, Stefos $T$ and Paschopoulos M. (2015): Hysteroscopy in women with abnormal uterine bleeding: a meta-analysis on four major endometrial pathology. Arch Gynecol Obstet, 291:1347-1354.

7. Kotdawala $\mathbf{P}$, Kotdawala $S$ and Nagar N. (2013): Evaluation of endometrium in peri-menopausal abnormal uterine bleeding. Journal of Mid-life Health, 4(1):16-22.

8. Nanda SS, Dash $S$ and Behera A. (2013): September. "Diagnostic value of hysteroscopy in perimenopausal abnormal uterine bleeding compared to histopathology study of blind dilatation \& curettage". Journal of Evolution of Medical and Dental Sciences, 2 (39):7497-505.

9. Pennant ME, Mehta $R$, Moody $P$, Hackett G, Prentice A, Sharp SJ and Lakshman R. (2017): Premenopausal 
abnormal uterine bleeding and risk of endometrial cancer. BJOG: An International Journal of Obstetrics \& Gynaecology, 1;124(3):404-11.

10. Shor S, Pansky M, Maymon R, Vaknin $Z$ and Smorgick N. (2019): Prediction of Pre-Malignant and Malignant Endometrial Polyps by Clinical and Hysteroscopy Features, The Journal of Minimally Invasive Gynecology, 10161018.

11. Singh S, Best C, Dunn S, Leyland $N$ and Wolfman W. (2013): AUB in Premenopausal Women. Journal of Obstetrics and Gynaecology, Canada, 35(5):S1 -S28.

12. Spadoto-Dias D, Bueloni-Dias FN, Elias LV, Leite NJ, Modotti WP, Lasmar RB and Dias R. (2016): The value of hysteroscopic biopsy in the diagnosis of endometrial polyps. Women's Health; 12(4):412-9.

13. Seshadri, L. (2016): Essentials of gynaecology. Pbl. Wolters kluwer india Pvt Ltd, pp. 103- 116.

14. Trojano, G., Damiani, G. R., Casavola, V. C., Loiacono, R., Malvasi, A., Pellegrino, A.,... and Battini, L. (2018): The role of hysteroscopy in evaluating postmenopausal asymptomatic women with thickened endometrium. Gynecology and Minimally Invasive Therapy, 7(1): 6 .

15. Van Hanegem $N$, Prins $M M$ and Bongers MY (2016): The accuracy of endometrial sampling in women with postmenopausal bleeding: a systematic review and meta-analysis. Eur J Obstet Gyn Reprod Biol, 197:147-155. 


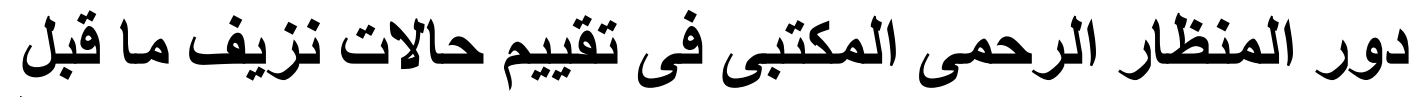

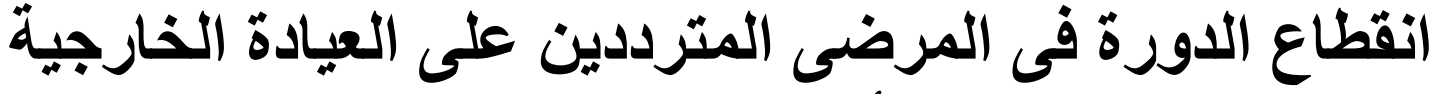

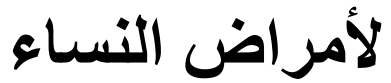

علاء حسن عبد المقصود محمد، محمد طاهر إسماعيل، يوسف السيد أبو شادى، طاهر محمد مصطفى

قسم التوليد وأمراض النساء، كلية الطب، جامعة الأزهر

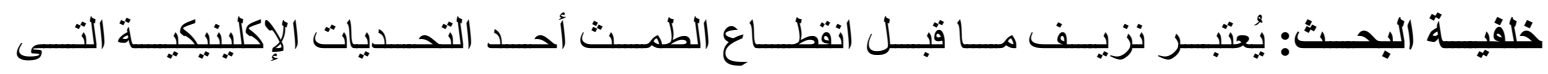

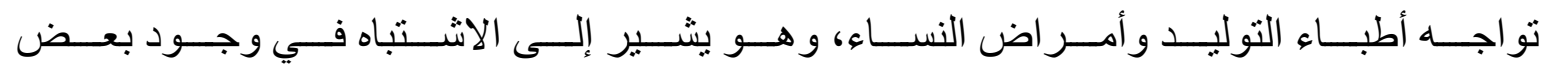

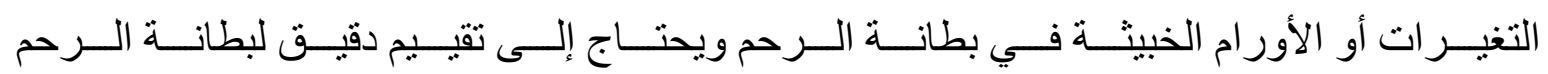

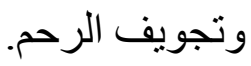

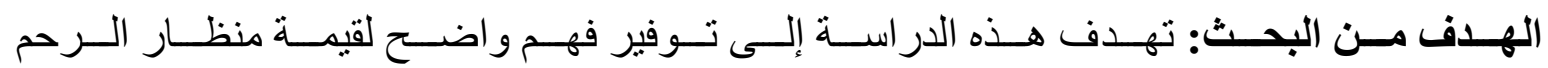

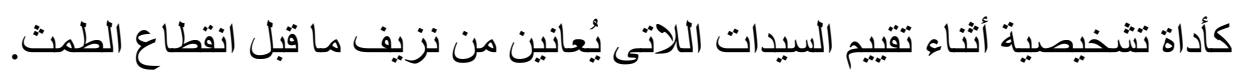

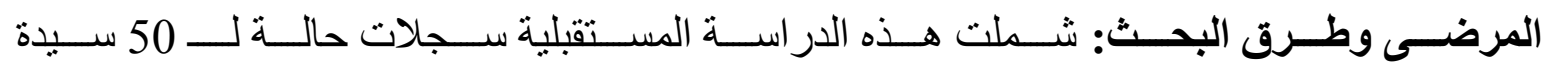

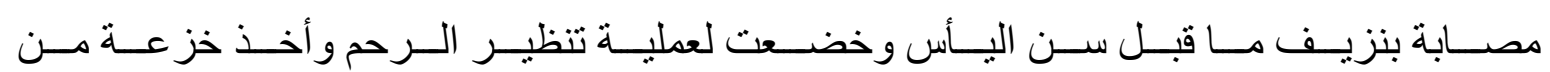

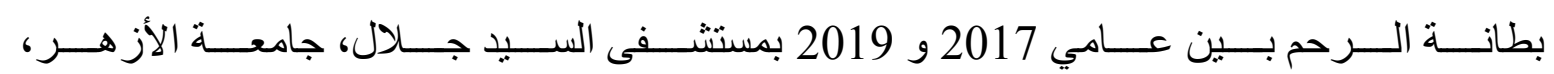

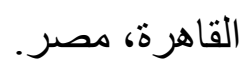

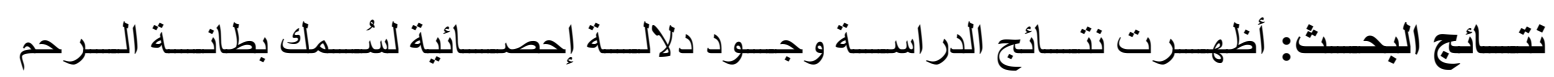

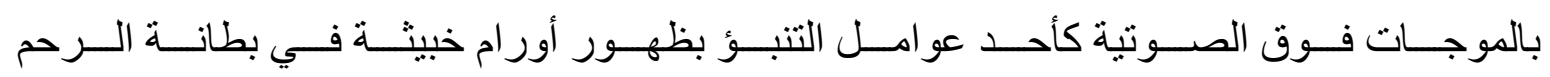

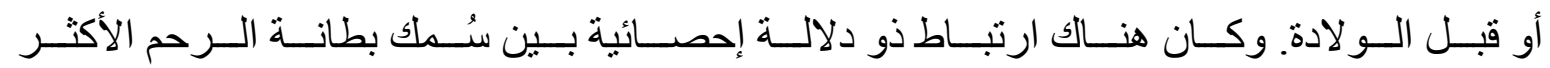

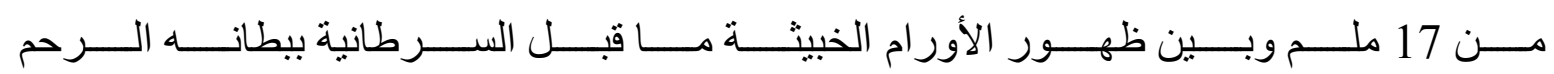

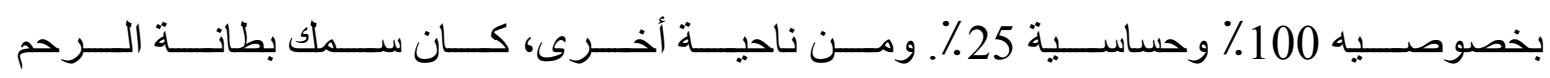

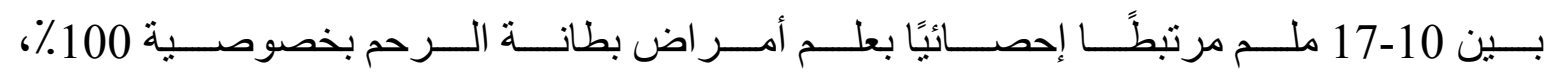

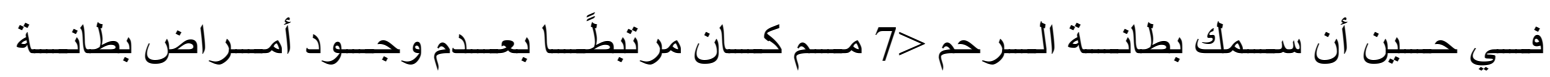

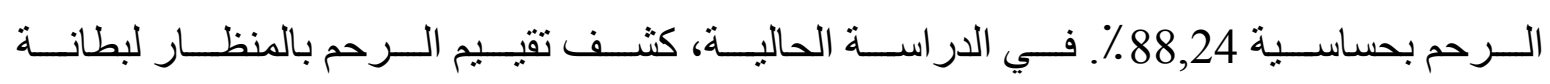

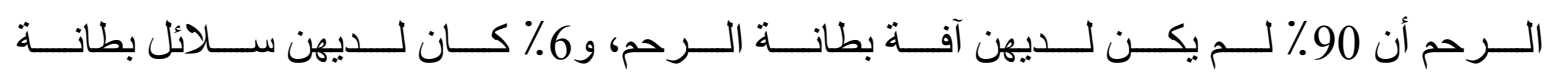

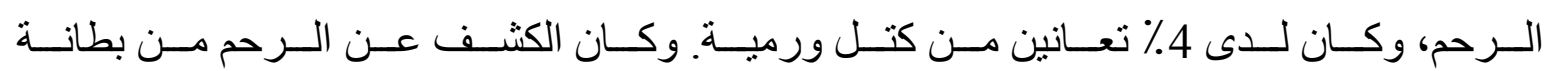




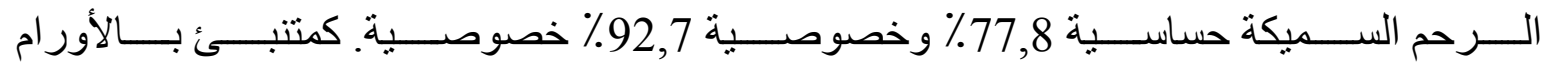

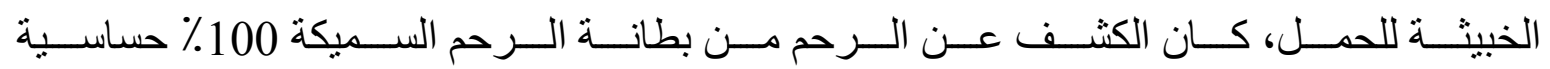

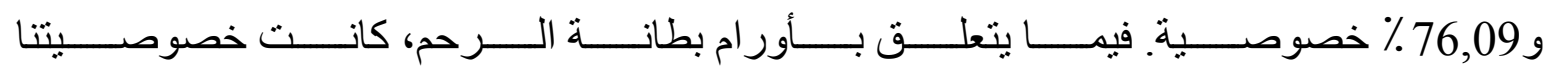

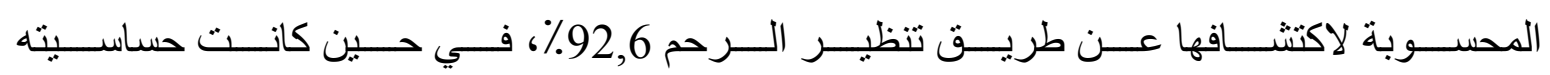

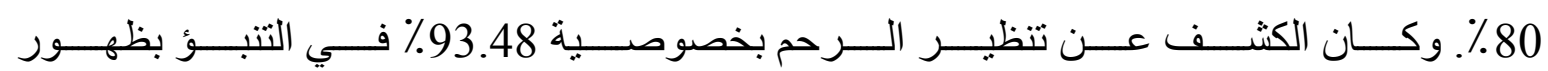

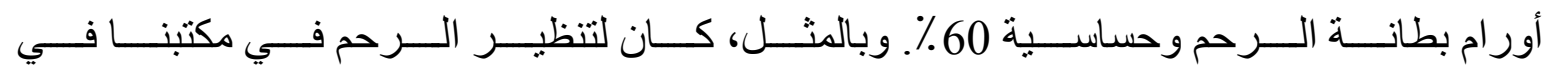

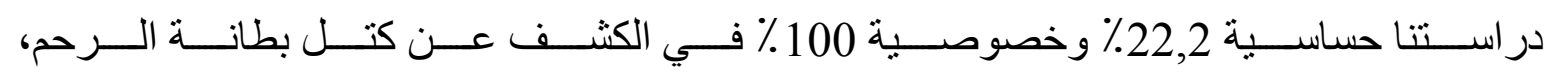

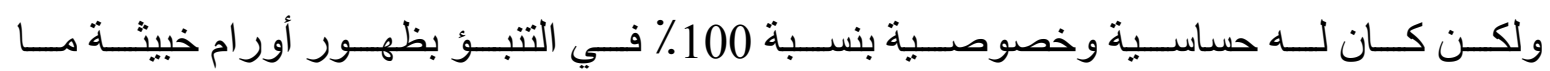

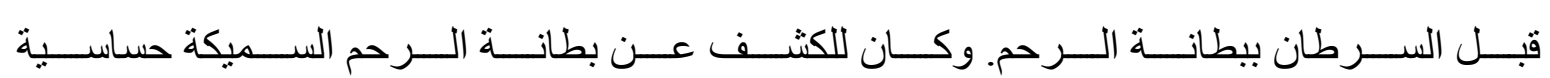

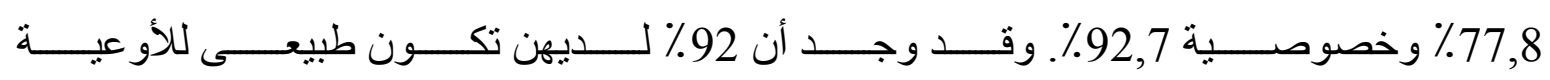

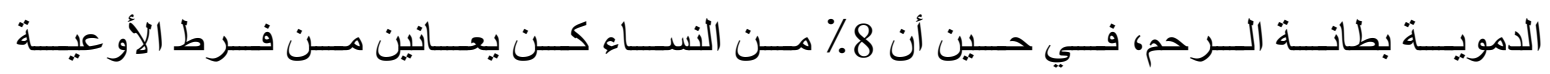

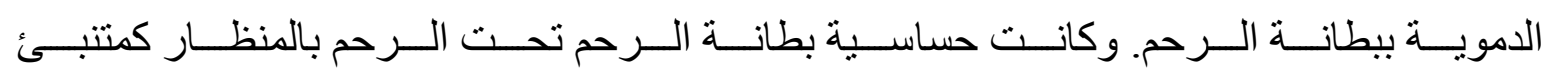

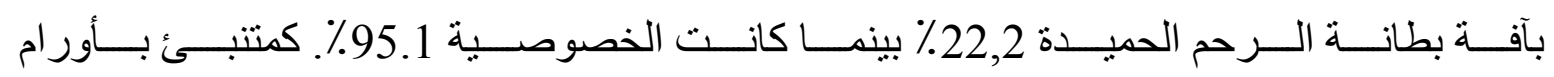

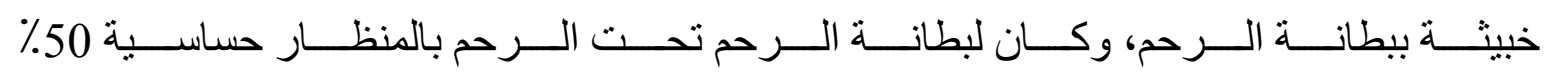
وخصوصية 95,6\% مما يشير إلى خصوصبة أعلى.

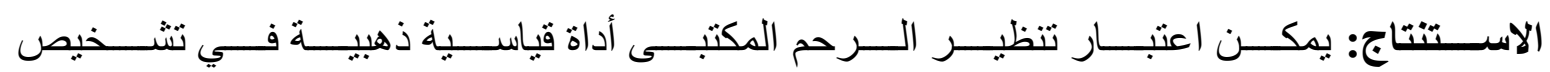

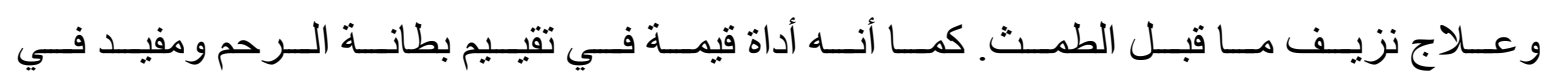
التخطيط للعلاج. 